\title{
A prospective observational study to assess PD-L1 expression in small biopsy samples for non-small-cell lung cancer
}

\author{
Akihito Tsunoda', Kei Morikawa ${ }^{1 *}$ (D, Takeo Inoue ${ }^{1}$, Teruomi Miyazawa ${ }^{1}$, Masahiro Hoshikawa², \\ Masayuki Takagi ${ }^{2}$ and Masamichi Mineshita ${ }^{1}$
}

\begin{abstract}
Background: Programmed cell death-1 (PD-1) immune checkpoint inhibitor antibody has proven to be effective in advanced non-small cell lung cancer (NSCLC) patients positive for programmed cell death-1 ligand-1 (PD-L1). However, there are currently no prospective studies evaluating PD-L1 expression for small biopsy samples.

Methods: To prospectively investigate the reliability of small samples for NSCLC, we included patients who underwent diagnostic biopsy by flexible bronchoscopy, computed tomography (CT) and ultra-sonography (US) guided coreneedle to determine the PD-L1 expression status. In pathologically confirmed NSCLC, PD-L1 expression was evaluated using companion diagnostic PD-L1 immunohistochemistry. We evaluated: 1) tumor cell count and sample size, 2) tumor proportion score (TPS): $<1,1-49 \%, 50 \% \leqq$, and 3) the concordance rate of TPS by biopsy and surgical samples.

Results: Of the 153 cases of PD-L1 expression, 110 were assessed using endobronchial ultrasonography guided transbronchial biopsy (EBUS-TBB) (thin bronchoscopy 84 cases; normal bronchoscopy 26 cases), 23 were endobronchial ultrasonography guided transbronchial needle aspiration (EBUS-TBNA), and 20 cases of CT or US-guided core-needle biopsy. Tumor cell count and sample size were significantly larger for normal bronchoscopy than thin bronchoscopy or EBUS-TBNA samples. Moreover, tumor cell counts for each subsequent biopsy decreased. In all cases, TPS distribution (undiagnosed, $<1 \%, 1-49,50 \% \leqq$ ) was $2.6,34.6,31.4,31.4 \%$, respectively. TPS positive cases using thin bronchoscope was 55.9\%, normal bronchoscope was $73.1 \%$ and EBUS-TBNA was $78.3 \%$. In early stage adenocarcinoma, TPS was lower compared with advanced stages. Conversely, in squamous cell carcinoma, the rates of TPS were similar regardless of stage. The concordance rate of TPS by biopsy and surgical materials was $86.7 \%$.
\end{abstract}

Conclusion: Utilizing smaller samples for evaluation, the frequency of TPS was comparable to past clinical trials using larger samples. The differences in TPS were influenced by diagnostic tools, cancer histologic types and staging. The concordance of TPS between EBUS-TBB samples and surgical materials was high.

Trial registration: This study was performed at the Department of Respiratory Medicine at St. Marianna University School of Medicine Hospital, with ethics approval (\#3590) and registered as a clinical trial (UMIN000027030).

Keywords: Lung cancer, Bronchoscopy, Pathology, Immunohistochemistry

\footnotetext{
* Correspondence: mokke@marianna-u.ac.jp

${ }^{1}$ Division of Respiratory Diseases, Department of Internal Medicine, St.

Marianna University School of Medicine, 2-16-1 Sugao, Miyamae-ku, Kawasaki

216-8511, Japan

Full list of author information is available at the end of the article
}

(c) The Author(s). 2019 Open Access This article is distributed under the terms of the Creative Commons Attribution 4.0 International License (http://creativecommons.org/licenses/by/4.0/), which permits unrestricted use, distribution, and reproduction in any medium, provided you give appropriate credit to the original author(s) and the source, provide a link to the Creative Commons license, and indicate if changes were made. The Creative Commons Public Domain Dedication waiver (http://creativecommons.org/publicdomain/zero/1.0/) applies to the data made available in this article, unless otherwise stated. 


\section{Background}

The development of immune checkpoint inhibitors has changed chemotherapy for non-small cell lung cancer (NSCLC) and other malignancies. In recent years, many immune checkpoint inhibitors were developed and approved after promising results in clinical trials. In Japan, nivolumab, pembrolizumab, and atezolizumab are approved for the treatment of advanced NSCLC [1-5].

Pembrolizumab is a humanized anti-programmed cell death 1 (PD-1) monoclonal antibody that inhibits PD-1 from binding to programmed cell death-1 ligand-1 (PD-L1). In a phase I clinical trial (KEYNOTE-001), pembrolizumab showed antitumor efficacy for patients with advanced NSCLC and PD-L1 positive expression [1]. This trial concluded that pembrolizumab was more effective in tumor cells with more than 50\% PD-L1 expression.

A phase III clinical trial (KEYNOTE-024) enrolled 305 previously untreated patients who were diagnosed with advanced NSCLC, with more than 50\% PD-L1 expression. This study revealed that pembrolizumab was more effective in progression-free survival, overall survival, and a higher response rate than platinum-based chemotherapy [4].

From these study results, approval of 22C3 assay was granted by the U.S. food and drug administration as a companion diagnostic to predict the clinical response to pembrolizumab treatment [6-9].

In Japan, small biopsy samples collected by bronchoscopic examination are often used for diagnosing lung cancer [10-13]. However, since surgically resected specimens and core-needle biopsy samples were used to estimate drug potency in past clinical trials, there is little known regarding the reliability of small biopsy samples $[14,15]$. In addition, although some studies evaluated the reliability of small biopsy samples, most of these studies were retrospective in nature, or were assessed by different antibodies [13-15].

\section{Methods}

\section{Aim and study design}

The aim of this study is to prospectively investigate the reliability of small samples for NSCLC cases to determine the status of PD-L1 expression. In pathologically confirmed NSCLC, PD-L1 expression was evaluated using companion diagnostic PD-L1 immunohistochemistry at our institution. We evaluated: 1) tumor cell count and sample size, 2) tumor proportion score (TPS): $<1,1-49 \%, 50 \% \leqq$ and 3 ) the concordance rate of TPS by biopsy and surgical samples.

\section{Patient selection}

We prospectively enrolled patients who underwent diagnostic biopsy procedures from March 2017 to August 2018. In this study, patients were examined through
Japan's health insurance, and written informed consent was obtained from all participants. Included patients were suspected of lung cell carcinoma by computed tomography $(\mathrm{CT})$ or positron emission tomography computed tomography (PET-CT) imaging. Diagnostic biopsy samples were obtained by flexible bronchoscopy and core-needle biopsy, at initial examination.

\section{Diagnostic procedures}

We selected the most appropriate diagnostic method for each case by taking into consideration patient safety and diagnostic rates. For bronchoscopic examinations, endobronchial ultrasonography (EBUS) (Endoscopic Ultrasound Center; EU-ME2, Olympus, Tokyo, Japan) was routinely used in combination with endobronchial ultrasonography guided transbronchial biopsy (EBUS-TBB) and endobronchial ultrasonography guided transbronchial needle aspiration (EBUS-TBNA) with flexible bronchoscope. EBUS-TBB was undertaken using a thin bronchoscope (BF-P260F, Olympus, Tokyo, Japan) or normal bronchoscope (BF-1 T260, Olympus, Tokyo, Japan). For EBUS-TBB, imaging of the peripheral pulmonary lesions was confirmed using a miniature ultrasound probe (UM-S20-17S, $20 \mathrm{MHz}$ center frequency, radial type, Olympus, Tokyo, Japan), and samples were obtained by a guide sheath kit (K-201, 203 guide-sheath kit, Olympus, Tokyo, Japan). After confirmation of the ultrasound probe within the target lesion, brushing and biopsy forceps were performed alternately, for a minimum of 5 times. EBUS-TBNA was undertaken using a flexible fiberscope (BF-UC260F, Olympus, Tokyo, Japan), and performed 2 to 3 times with a 22-gauge needle (Single Use Aspiration Needle; NA-201SX-4022, Olympus, Tokyo, Japan). CT-guided core needle biopsy was performed 2 to 3 times with a semi-automatic aspiration device (Temno Evolution, Care Fusion Japan, Tokyo, Japan). The needle size was 20 gauge, and the length of the needle was 11 or $15 \mathrm{~cm}$. US-guided core needle biopsy was usually performed at least 3 times.

\section{Pathological diagnosis}

Pathological diagnosis was conducted by pathologist using hematoxylin-eosin (HE) stained slides. After the diagnosis of NSCLC, PD-L1 immunohistochemistry staining of each biopsy sample was conducted and assessed by at least two pathologists.

The samples, which were formalin-fixed and paraffinembedded, were sliced at a thickness of $4 \mu \mathrm{m}$. The sections were processed for $20 \mathrm{~min}$ at $97^{\circ} \mathrm{C}$ for deparaffinized and inactivating enzymes. Sequentially, the samples were stained for PD-L1 with an anti-human PD-L1 antibody. PD-L1 expression was evaluated in our institution using companion diagnostic PD-L1 immunohistochemistry (IHC) (PD-L1 IHC 22C3, pharmDx, Dako/ 

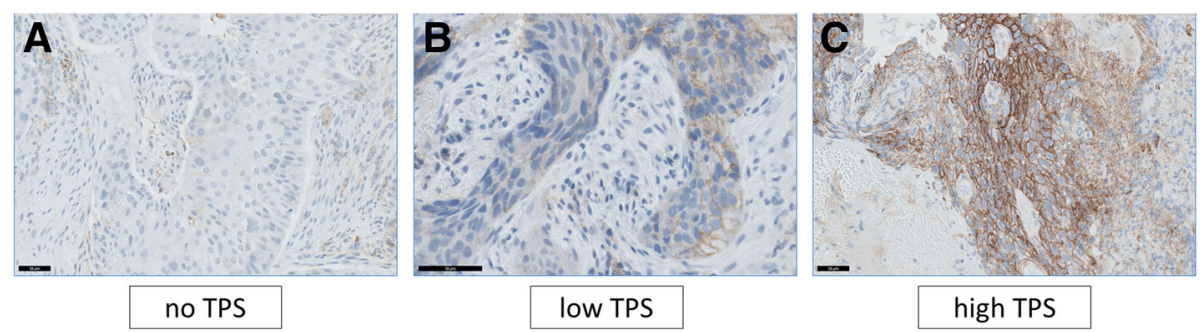

Fig. 1 The typical cases for each TPS level: <1, 1-49\%, 50\%ฏ. a The TPS was under 1\%; no TPS. b The TPS was 20\%; low TPS. c The TPS was 80\%; high TPS. The TPS level was evaluated by pathologists who completed training courses in TPS estimationTPS: tumor proportion score

Agilent, Santa Clara, United States) with autostainer Link 48, detecting driver mutation in parallel. Following the standard recommendation of previous publications, PD-L1 protein expression was determined by TPS, which is the percentage of viable tumor cells showing partial or complete membrane staining. PD-L1 expression was classified into three levels: no TPS $(<1 \%)$, low TPS (1-49\%), and high TPS (50\%@). Figure 1 shows typical cases for each TPS level. Using HE and PD-L1 stained slides, we manually assessed the number of tumor cells, the sample size (diameter), the crush rate with a cut-off value of $<5,5-50 \%, 50 \%<$, and the TPS for each biopsy sample using the slide that contained the most tumor cells.

\section{Comparison of small biopsy samples and surgical specimens}

In patients assessed as early stage NCSLC by diagnostic procedures, small biopsy and resected specimens were

Table 1 Characteristics of Patients

\begin{tabular}{|c|c|c|c|c|}
\hline & \multicolumn{4}{|c|}{ Biopsy Methods } \\
\hline & $\begin{array}{l}\text { TBB } \\
\text { (BF: P260F) }\end{array}$ & $\begin{array}{l}\text { TBB } \\
\text { (BF: 1 T260) }\end{array}$ & TBNA & $\begin{array}{l}\text { Core-needle } \\
\text { (CT or US) }\end{array}$ \\
\hline Patients & 84 & 26 & 23 & 20 \\
\hline \multicolumn{5}{|l|}{ Age } \\
\hline Mean & 73.4 & 68.6 & 68.3 & 65.9 \\
\hline Range & $49-88$ & $45-84$ & $48-88$ & $42-93$ \\
\hline \multicolumn{5}{|l|}{ Sex } \\
\hline Male & 56 & 20 & 16 & 14 \\
\hline Female & 28 & 6 & 7 & 6 \\
\hline \multicolumn{5}{|c|}{ Smoking status } \\
\hline Current/Ex & 70 & 23 & 21 & 18 \\
\hline Never & 14 & 3 & 2 & 2 \\
\hline \multicolumn{5}{|c|}{ Pathological subtypes } \\
\hline Adeno & 59 & 7 & 13 & 12 \\
\hline Squamous & 23 & 18 & 9 & 5 \\
\hline Others & 2 & 1 & 1 & 3 \\
\hline
\end{tabular}

TBB transbronchial biopsy, TBNA transbronchial needle aspiration, Adeno adenocarcinoma, Squamous: squamous cell carcinoma compared from the standpoint of TPS after surgical operation. We evaluated the concordance rate for TPS, which was under the $20 \%$ threshold to differentiate between small biopsy and surgical specimen.

\section{Statistical analysis}

JMP pro 13 (SAS Institute Japan, Tokyo, Japan) was used for statistical analysis. We analyzed the differences of tumor cell counts and sample sizes in each method non-parametrically using the Wilcoxon rank-sum test. A $P$-value of less than 0.05 was considered statistically significant.

\section{Results}

A total of 153 patients were eligible for this study. Patients' characteristics are shown in Table 1. The biopsy methods performed for each case were: 110 for EBUSTBB; 84 for thin bronchoscope, 26 for normal bronchoscope; 23 for EBUS-TBNA, and 20 cases were core-needle

Table 2 Tumor cell counts, crush artifact or necrotic changes, and sample size for each method

\begin{tabular}{lllll}
\hline & $\begin{array}{l}\text { TBB } \\
\text { (BF: P260F) }\end{array}$ & $\begin{array}{l}\text { TBB } \\
\text { (BF: 1 T260) }\end{array}$ & TBNA & $\begin{array}{l}\text { Core-needle } \\
\text { (CT or US) }\end{array}$ \\
\hline $\begin{array}{l}\text { Sample number } \\
\text { Tumor cell counts }\end{array}$ & 84 & 26 & 23 & 20 \\
$<100$ & 11 & 0 & 0 & 0 \\
$100 \leqq,<1000$ & 56 & 3 & 14 & 3 \\
$1000 \leqq,<2000$ & 14 & 3 & 0 & 5 \\
$2000<$ & 3 & 20 & 9 & 12 \\
Median & 559 & 6953 & 1968 & 6593 \\
Range & $30-3000$ & $380-30,000$ & $100-9000$ & $100-37,500$
\end{tabular}

Crush artifact or necrotic change, \%

$\begin{array}{lllll}<5 & 15 & 17 & 12 & 14 \\ 5-50 & 39 & 6 & 8 & 4 \\ 50< & 30 & 3 & 3 & 2\end{array}$

Diameter of biopsy sample, mm, mean (95\% C.I.)

$\begin{array}{lllll}\text { Major axis } & 1.3( \pm 0.1) & 3.2( \pm 0.9) & 1.6( \pm 0.4) & 6.3( \pm 1.7) \\ \text { Minor axis } & 1.0( \pm 0.1) & 2.2( \pm 0.6) & 1.3( \pm 0.4) & 1.1( \pm 0.8)\end{array}$

TBB transbronchial biopsy, TBNA transbronchial needle aspiration 
Table 3 -value for each method

\begin{tabular}{lll}
\hline & $P$-value & \\
\cline { 2 - 3 } & tumor cell count & sample size \\
\hline BF P260F vs 1 T260 & $p<0.0001$ & $p<0.0001$ \\
BF P260F vs TBNA & $p=0.0128$ & $p=0.2317$ \\
BF P260F vs core needle & $p<0.0001$ & $p<0.0001$ \\
BF 1 T260 vs TBNA & $p=0.0004$ & $p<0.0001$ \\
BF 1 T260 vs core needle & $p=0.7229$ & $p=0.0027$ \\
TBNA vs core needle & $p=0.0057$ & $p<0.0001$ \\
\hline
\end{tabular}

TBNA transbronchial needle aspiration

biopsy. For pathological subtypes, 59.5\% were adenocarcinoma, $35.9 \%$ were squamous cell carcinoma, and $4.6 \%$ were others. Smoking histories were observed for $86.3 \%$ of patients.

Table 2 shows the number of tumor cells, crush artifact or necrotic changes, and sample sizes of each specimen and for each method. Ninety-three percent of cases contained enough tumor cells (over 100 tumor cells) for TPS evaluation. Normal size bronchoscope biopsy method was able to obtain more tumor cells than thin bronchoscope. In small samples that were obtained by thin bronchoscopy, $35.7 \%$ of cases showed a crush artifact rate of more than $50 \%$. In this study, the sample sizes for normal bronchoscope and core-needle were significantly larger compared with other methods (Table 3 ).

Figure 2a shows the percentage of TPS for all pathological cases. The ratio of high TPS was $31.4 \%$, low TPS was $31.4 \%$ and no TPS was $34.6 \%$. While squamous cell carcinoma represented $72.7 \%$ of TPS positive cases, adenocarcinoma was comprised of $57.2 \%$. For each method, TPS positive cases using thin bronchoscope was $55.9 \%$, normal bronchoscope was $73.1 \%$, and EBUSTBNA was $78.3 \%$ (Fig. 2b).
Table 4 shows TPS expression by cancer stage. In adenocarcinoma, early stage cases (stageI and II), showed 16.1\% high TPS compared to advanced stage cases (stage III and IV), with $34.5 \%$. In early stage cases, $48.4 \%$ showed no TPS. In squamous cell carcinoma, the rates of TPS were similar regardless of stage.

Tumor cell counts in biopsy samples for each method are shown in Fig. 3. We were able to obtain over 100 tumor cells in nearly every case, which is necessary for evaluating PD-L1 expression. These results showed that earlier samples obtained more tumor cells. However, after the first biopsy, the number of tumor cells for subsequent biopsies decreased. In 11 cases, there were less than 100 tumor cells per sample.

Table 5 shows a comparison of PD-L1 expression between smaller biopsy samples and surgical specimens in 30 cases. Smaller biopsies were taken by thin bronchoscope. The concordance rate was $86.7 \%$, which was under the $20 \%$ threshold to differentiate TPS between small biopsy and resected samples. Additional file 1 shows all raw data of this study.

\section{Discussion}

This is the first report, to our knowledge, to prospectively investigate TPS for small biopsy samples in clinical practice. Bronchoscopic examinations are widely conducted as an initial diagnostic procedure. Hence, the assessment of reliability for small samples is important in the decision-making process for induction of immuno-checkpoint inhibitor as a first line treatment $[1,4,5,13-15]$.

For each case in this study, the ratio of TPS $(<1,1-$ $49 \%, 50 \% \leqq$ ) was approximately equal to past studies [5]. In a previous report outlining TPS assessment guidelines, samples should contain at least 100 tumor cells for
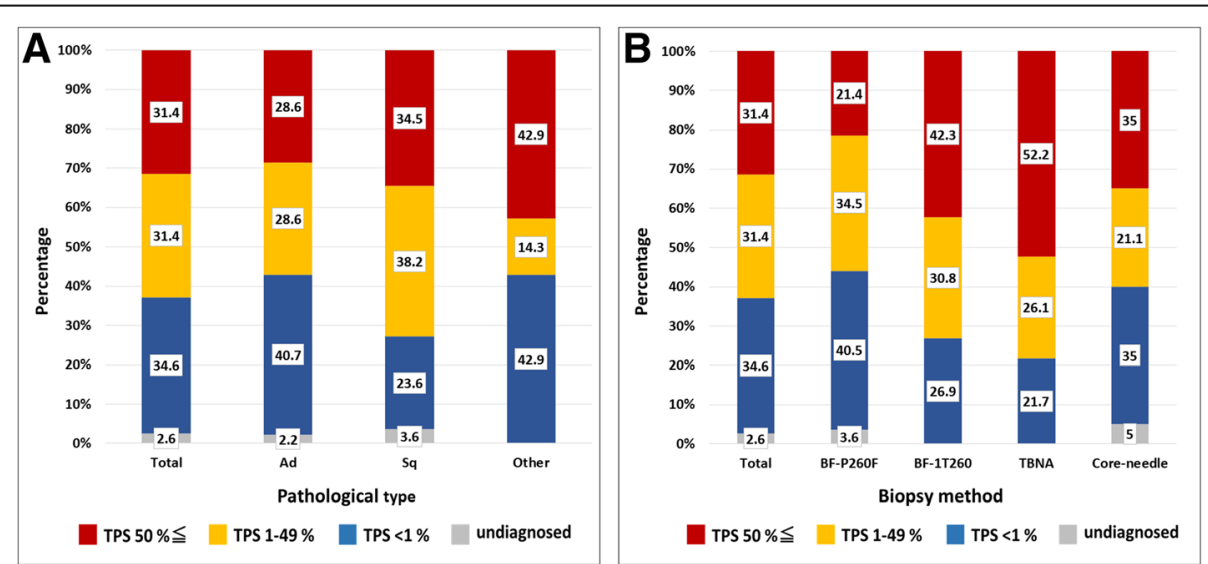

Fig. 2 a The total percentage of TPS for each pathological case. $\mathbf{b}$ The total percentage of TPS for each biopsy method. Red indicates high TPS $(50 \% \leqq)$, yellow indicates low TPS (1-49\%), and blue indicates no TPS (<1\%). Gray indicates undiagnosed cases. Ad: adenocarcinoma, Sq: squamous cell carcinoma. TBNA: transbronchial needle aspiration 
Table 4 The difference of TPS by staging

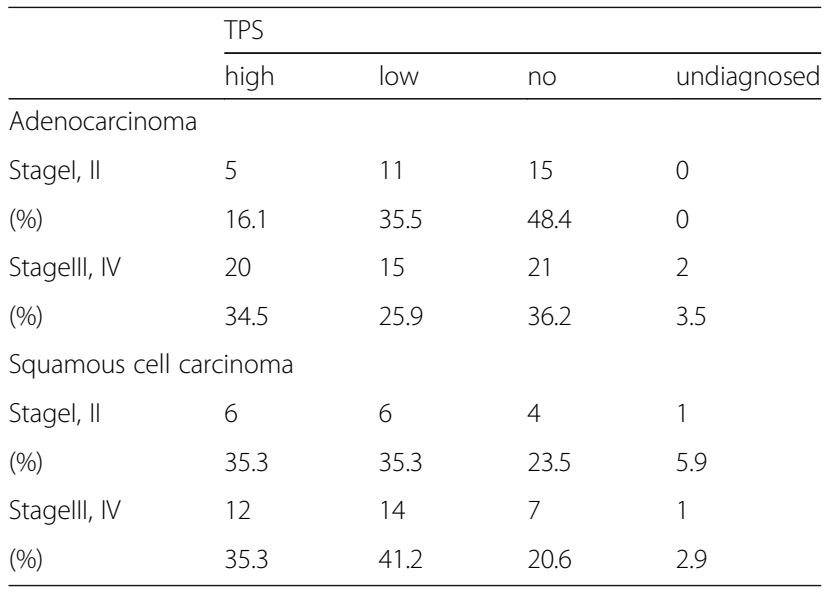

TPS assessment [16]. Although there were differences in the sample sizes for each method, we were able to obtain at least 100 tumor cells for our small samples. In particular, this study revealed the differences in specimen size between thin bronchoscopy, normal bronchoscopy and other methods. Moreover, our approach revealed that tumor cells from subsequent biopsies decreased which might be due to localized bleeding from repeated biopsies. Therefore, the first and second biopsy samples are considered important for the evaluation of TPS. When there were less than 100 tumor cells per sample, we collected subsequent samples and combined these on one slide for TPS evaluation.

For each pathological subtype, the ratio of TPS positive cases was higher in squamous cell carcinoma as previously reported [17]. These cases were more likely located in the central airway and therefore, normal bronchoscopy could easily reach the target lesion and collect an appropriate specimen size.

For adenocarcinoma cases, there were some differences observed for TPS between early and advanced cancer stages. It has been suggested that PD-L1 expression increases as the stage of cancer advances. On the other hand, in squamous cell carcinoma, there were no significant differences seen for TPS between early and advanced stage cases. Differences in the pathological diagnosis and cancer staging might influence PD-L1 expression [17-19].

The samples that were obtained by thin bronchoscope tended to collect less tumor cells and show low TPS. This was mainly due to early stage adenocarcinoma, located at the pulmonary peripheral areas, which tended to show low TPS [20]. Another explanation might be that the crush artifact rates were relatively higher for thin bronchoscope samples as previously reported [13]. However, for the comparison of bronchoscopic specimens, which were obtained by thin bronchoscopy or surgically resected, the TPS concordance was relatively high which contrasts with previous retrospective reports $[14,15]$.
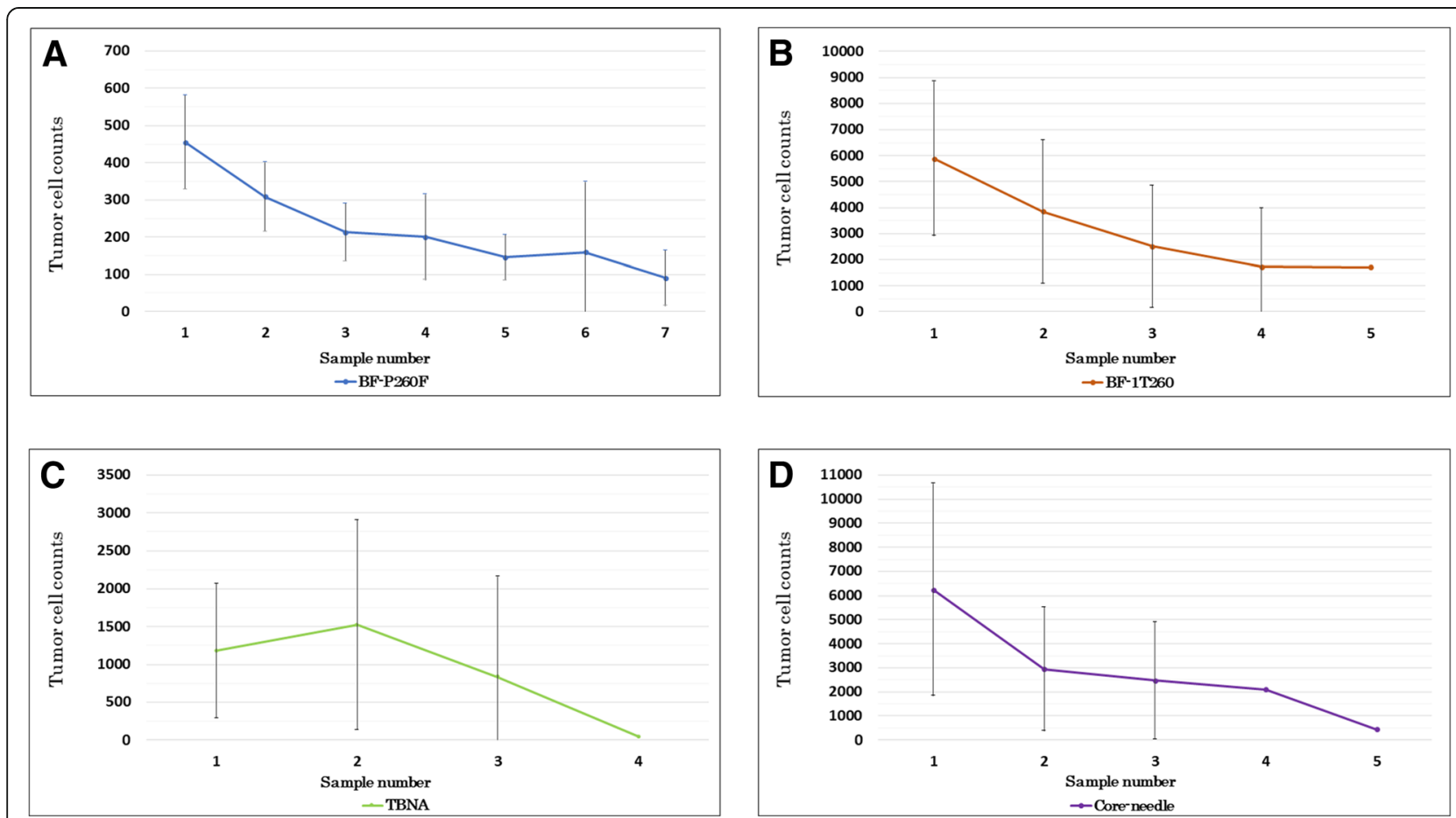

Fig. 3 The subsequent median number of tumor cell counts with 95\% confidential interval for each biopsy method. a Comparison of tumor cells using thin bronchoscopy (BF-P260F), (b) normal bronchoscopy (BF-1 T260), (c) EBUS-TBNA, and (d) CT or US-guided core-needle biopsy. EBUS-TBNA: endobronchial ultrasonography - transbronchial needle aspiration. CT: computed-tomography. US: ultra-sonography 
Table 5 The comparison of PD-L1 expression between small biopsy samples and surgical specimens

\begin{tabular}{|c|c|c|c|c|c|c|c|c|c|c|}
\hline Case & Sex & Smoking & Location & Pathology (dominant \%) & $\begin{array}{l}\text { Size of } \\
\text { lesion (mm) }\end{array}$ & SUV max & $\mathrm{BF}$ & $\begin{array}{l}\text { Tumor cell } \\
\text { count for BF }\end{array}$ & $\begin{array}{l}\text { TPS in } \\
\text { BF (\%) }\end{array}$ & $\begin{array}{l}\text { TPS in } \\
\text { operation (\%) }\end{array}$ \\
\hline 1 & $\mathrm{~F}$ & never & Ling & Ad (papi 85) & $24 \times 20$ & 4.0 & P260F & 700 & 0 & 10 \\
\hline 2 & M & former & $\mathrm{RL}$ & Ad (acinar 70) & $17 \times 13$ & 4.0 & P260F & 160 & 0 & 0 \\
\hline 3 & M & former & Ling & Ad (enteric) & $18 \times 18$ & 5.6 & P260F & 600 & 0 & 10 \\
\hline 4 & M & current & $\mathrm{LL}$ & Pleomorphic & $40 \times 28$ & 8.1 & P260F & 500 & 50 & 100 \\
\hline 5 & M & current & RL & $\mathrm{Sq}$ & $40 \times 35$ & 13.4 & P260F & 400 & 20 & 30 \\
\hline 6 & $\mathrm{~F}$ & never & LU & Ad (lepidic 90) & $17 \times 16$ & 4.1 & P260F & 140 & 70 & 70 \\
\hline 7 & $\mathrm{~F}$ & former & $L U$ & Ad (papi 70) & $25 \times 22$ & 4.6 & P260F & 1200 & 0 & 10 \\
\hline 8 & M & former & $\mathrm{RU}$ & Ad (lepi/aci 60/30) & $27 \times 25$ & 20.4 & P260F & 800 & 0 & 0 \\
\hline 9 & $\mathrm{~F}$ & never & LU & Ad (solid/lepi 60/30) & $25 \times 18$ & 9.4 & P260F & 70 & 50 & 0 \\
\hline 10 & $\mathrm{~F}$ & never & $\mathrm{LL}$ & Ad (lepi/aci/papi 50/20/20) & $25 \times 25$ & 3.9 & P260F & 280 & 0 & 0 \\
\hline 11 & M & former & $\mathrm{LL}$ & Ad (papi 60) & $18 \times 16$ & 6.3 & P260F & 220 & 50 & 30 \\
\hline 12 & $\mathrm{~F}$ & former & $\mathrm{RU}$ & Ad (papi/lepi 90/10) & $15 \times 12$ & 3.1 & P260F & 170 & 0 & 0 \\
\hline 13 & M & former & $\mathrm{LL}$ & Ad (solid 100) & $43 \times 40$ & 11 & P260F & 160 & 90 & 100 \\
\hline 14 & $\mathrm{~F}$ & never & LU & Ad (aci/lepi/papi/micropapi 40/20/20/20) & $18 \times 17$ & 2.2 & P260F & 120 & 40 & 10 \\
\hline 15 & M & former & $\mathrm{RU}$ & Ad (papi/lepi/solid 30/10/10) & $27 \times 24$ & 2.9 & P260F & 340 & 20 & 10 \\
\hline 16 & M & former & LU & Ad (solid//papi/aci 50/30/20) & $26 \times 12$ & 3.2 & P260F & 220 & 0 & 0 \\
\hline 17 & M & former & $\mathrm{RU}$ & Ad (aci/lepi/papi 65/30/5) & $36 \times 20$ & 5.3 & P260F & 530 & 30 & 30 \\
\hline 18 & M & former & RL & Mucinous & $64 \times 29$ & 9.3 & P260F & 450 & 0 & 0 \\
\hline 19 & M & former & LU & Squamous & $20 \times 15$ & 8 & P260F & 450 & 30 & 10 \\
\hline 20 & $\mathrm{~F}$ & former & $\mathrm{RU}$ & Squamous & $12 \times 8$ & 14.2 & P260F & 1000 & 0 & 0 \\
\hline 21 & M & never & $\mathrm{RU}$ & Ad (papi/aci/lepi/micropapi 60/20/10/10) & $33 \times 20$ & 3.4 & P260F & 100 & 0 & 10 \\
\hline 22 & M & former & $\mathrm{RU}$ & Ad (papi/lepi 60/40) & $35 \times 25$ & 6 & P260F & 100 & 30 & 0 \\
\hline 23 & $\mathrm{~F}$ & former & RM & Ad (papi/lepi/aci 60/20/20) & $23 \times 18$ & 3.8 & P260F & 700 & 0 & 10 \\
\hline 24 & M & former & $\mathrm{RU}$ & Ad (micropapi/aci/papi/lepi 50/20/20/10) & $13 \times 13$ & 3.1 & P260F & 600 & 10 & 20 \\
\hline 25 & M & former & LU & Mucinous & $25 \times 23$ & 1.7 & P260F & 200 & 10 & 0 \\
\hline 26 & M & former & RM & Large & $30 \times 25$ & 4.8 & P260F & 200 & 70 & 90 \\
\hline 27 & M & former & $\mathrm{RU}$ & Mucinous & $70 \times 35$ & 8.2 & P260F & 300 & 0 & 0 \\
\hline 28 & M & former & $\mathrm{RU}$ & Squamous & $45 \times 20$ & 7 & P260F & 350 & 0 & 0 \\
\hline 29 & $\mathrm{~F}$ & former & $\mathrm{RU}$ & Ad (solid/papi 80/20) & $45 \times 38$ & 14.1 & P260F & 1000 & 20 & 0 \\
\hline 30 & $\mathrm{~F}$ & former & LU & Squamous & $50 \times 30$ & 4.8 & P260F & 50 & 0 & 10 \\
\hline
\end{tabular}

Aci acinar, Papi papillary, lepi lepidic, micropapi micropapillary, SUV standardized uptake value, $R U$ right upper lobe, $R M$ right middle lobe, $R L$ right lower lobe, $L U$ left upper segment, Ling left lingular segment, $L L$ left lower lobe

There were some limitations observed in this study. First, this study was performed at a single institution; therefore, these results should be compared against larger multi-center studies. Second, there were less cases for normal bronchoscope, EBUS-TBNA, and core-needle in compared to the number of cases using thin bronchoscope. However, we believe this study emulates realworld circumstances since there are more instances to perform thin bronchoscope. Third, this study included eight post chemotherapy patients (re-biopsy) and seven recurrences after surgery. It could be suggested that these treatments may have influenced PD-L1 expression as previous papers have reported [21]. Forth, this study focused on TPS data only; however, we plan to further evaluate the response of other immune checkpoint inhibitors in future studies.

\section{Conclusion}

Small biopsy samples obtained by bronchoscopy were deemed appropriate to evaluate TPS, and the frequency of TPS was comparable to past clinical trials using larger samples for evaluation. Differences in TPS were observed according to diagnostic tools, cancer histologic types and staging. The TPS concordance rate between EBUS-TBB samples and surgical materials was high. 


\section{Additional file}

Additional file 1: The raw data of all cases in this study. (PDF $252 \mathrm{~kb}$ )

\section{Abbreviations}

EBUS: Endobronchial ultrasonography; EBUS-TBB: Endobronchial ultrasonography transbronchial biopsy; EBUS-TBNA: Endobronchial ultrasonography transbronchial needle aspiration; NSCLC: Non-small cell lung cancer; PD1: Programmed cell death 1; PD-L1: Programmed cell death-1 ligand-1; TPS: Tumor proportion score

\section{Acknowledgements}

The authors thank Naoki Shimada, Hironao Kusakari and Chie Okawa from St. Marianna University School of Medicine, Department of Pathological Diagnosis for preparing specimen slides for all cases. The authors also thank Mr. Jason Tonge from St. Marianna University School of Medicine for the linguistic review of this manuscript.

\section{Authors' contributions}

A. T. had full access to data in the study and takes responsibility for the integrity and accuracy of data analysis. K. M. contributed to study design and interpretation. M. H. and M. T. contributed to pathological procedures and TPS evaluation. T. I., T. M., and M. M. contributed to the scientific review and final approval of this manuscript. All authors read and approved the final manuscript.

\section{Authors' information}

This study was partially presented at the 18th World Conference on Lung Cancer 2017, Yokohama, Japan (October 17, 2017) and the European Society for Medical Oncology congress 2018, Munich, Germany (October 21, 2018).

\section{Funding}

This research received no specific grant from any funding agency.

\section{Availability of data and materials}

All data generated or analyzed during this study are included in this published article and its Additional file 1.

\section{Ethics approval and consent to participate}

This study was performed at the Department of Respiratory Medicine at St. Marianna University School of Medicine Hospital, with ethics approval (human research and ethics committee approval reference number 3590) and registered as a clinical trial UMIN000027030. In this study, written informed consent was obtained from all participants.

\section{Consent for publication}

Not applicable.

\section{Competing interests}

The authors have no financial or commercial associations that would be considered a conflict of interest in relation to this study.

\section{Author details}

'Division of Respiratory Diseases, Department of Internal Medicine, St. Marianna University School of Medicine, 2-16-1 Sugao, Miyamae-ku, Kawasaki 216-8511, Japan. ${ }^{2}$ Department of Pathological Diagnosis, St. Marianna University School of Medicine, 2-16-1 Sugao, Miyamae-ku, Kawasaki 216-8511, Japan.

Received: 18 March 2019 Accepted: 29 May 2019 Published online: 07 June 2019

\section{References}

1. Garon EB, Rizvi NA, Hui R, Leighl N, Balmanoukian AS, Eder JP, Patnaik A, Aggarwal C, Gubens M, Horn L, et al. Pembrolizumab for the treatment of non-small-cell lung cancer. N Engl J Med. 2015;372(21):2018-28 https:// www.nejm.org/doi/full/10.1056/NEJMoa1501824.

2. Borghaei $H$, Paz-Ares L, Horn L, Spigel DR, Steins M, Ready NE, Chow LQ, Vokes EE, Felip E, Holgado E, et al. Nivolumab versus docetaxel in advanced nonsquamous non-small-cell lung cancer. N Engl J Med. 2015;373(17):1627-39 https://www.nejm.org/doi/full/10.1056/NEJMoa1507643.

3. Brahmer J, Reckamp KL, Baas P, Crinò L, Eberhardt WE, Antonia S, Pluzanski A, Vokes EE, Holgado E, Waterhouse D, et al. Nivolumab versus docetaxel in advanced squamous-cell non-small-cell lung cancer. N Engl J Med. 2015; 373(2):123-35 https://www.nejm.org/doi/full/10.1056/NEJMoa1504627.

4. Reck M, Rodríguez-Abreu D, Robinson AG, Hui R, Csőszi T, Fülöp A, Gottfried M, Peled N, Tafreshi A, Cuffe S, et al. Pembrolizumab versus chemotherapy for PD-L1-positive non-small-cell lung cancer. N Engl J Med. 2016;375:1823-33 https://www.nejm.org/doi/full/10.1056/NEJMoa1606774.

5. Herbst RS, Baas P, Kim DW, Felip E, Pérez-Gracia JL, Han JY, Molina J, Kim JH, Arvis CD, Ahn MJ, et al. Pembrolizumab versus docetaxel for previously treated, PD-L1-positive, advanced non-small-cell lung cancer (KEYNOTE-010): a randomised controlled trial. Lancet. 2016;387:1540-50 https://www. thelancet.com/journals/lancet/article/PIIS0140-6736(15)01281-7/fulltext.

6. Dako. PD-L1 IHC 22C3 pharmDx. https://www.agilent.com/cs/library/ usermanuals/public/29165-JP-ROW_22C3_IM.pdf. Accessed 2, Oct 2016.

7. Neuman T, London M, Kania-Almog J, Litvin A, Zohar Y, Fridel L, Sandbank J, Barshak I, Vainer GW. A harmonization study for the use of 22C3 PD-L1 immunohistochemical staining on Ventana's platform. J Thorac Oncol. 2016; 11:1863-8 https:/www.jto.org/article/S1556-0864(16)30931-5/fulltext.

8. Marchetti A, Barberis M, Franco R, De Luca G, Pace MV, Staibano S, Volante M, Buttitta F, Guerini-Rocco E, Righi L, et al. Multicenter comparison of 22C3 PharmDx (Agilent) and SP263 (Ventana) assays to test PD-L1 expression for NSCLC patients to be treated with immune checkpoint inhibitors. J Thorac Oncol. 2017;12(11):1654-63 https://www.jto.org/article/S1556-0864(17)30662-7/ fulltext.

9. Ilie M, Khambata-Ford S, Copie-Berqman C, Huang L, Juco J, Hofman V, Hofman P. Use of the 22C3 anti-PD-L1 antibody to determine PD-L1 expression in multiple automated immunohistochemistry platforms. PLoS One. 2017;12(8):e0183023 https://journals.plos.org/plosone/article?id=10. 1371/journal.pone.0183023.

10. Miliman N, Faurschou P, Munch EP, Grode G. Transbronchial lung biopsy through the fibre optic bronchoscope. Results and complications in 452 examinations. Respir Med. 1994;88(10):749-53 https://www.sciencedirect. com/science/article/pii/S0954611105801970.

11. Okamoto H, Watanabe K, Nagatomo A, Kunikane H, Aono H, Yamagata T, Kase M. Endobronchial ultrasonography for mediastinal and hilar lymph node metastases of lung cancer. Chest. 2002;121(5):1498-506 https://journal. chestnet.org/article/S0012-3692(15)34862-5/fulltext.

12. Yasufuku K, Chiyo M, Sekine Y, Prashant NC, Shibuya K, lizasa T, Fujisawa T. Real-time endobronchial ultrasound-guided transbronchial needle aspiration of mediastinal and hilar lumph nodes. Chest. 2004;126(1):122-8 https:// journal.chestnet.org/article/S0012-3692(15)32904-4/fulltext.

13. Sakakibara R, Imamura K, Tambo Y, Ninomiya H, Kitazono S, Yanagitani N, Horiike A, Ohyanagi F, Nakao M, Mun M, et al. EBUS-TBNA as a promising method for evaluation of tumor PD-L1 expression in lung cancer. Clin Lung Cancer. 2017;18(5):527-34 https://www.clinical-lung-cancer.com/article/ S1525-7304(16)30378-3/fulltext

14. Ilie M, Long-Mira E, Bence C, Butori C, Lassalle S, Bouhlel L, Fazzalari L, Zahaf K, Lalvée S, Washetine K, et al. Comparative study of the PD-L1 status between surgically resected specimens and matched biopsies of NSCLC patients reveal major discordances: a potential issue for anti-PD-L1 therapeutic strategies. Ann Oncol. 2016;27(1):147-53 https://academic. oup.com/annonc/article/27/1/147/2196310.

15. Kitazono S, Fujikawa Y, Tsuta K, Utsumi H, Kanda S, Horinouchi H, Nokihara H, Yamamoto N, Sasada S, Watanabe S, et al. Reliability of small biopsy samples compared with resected specimens for the determination of programmed death-ligand 1 expression in non-small-cell lung cancer. Clin Lung Cancer. 2015;16(5):385-90 https://www.sciencedirect.com/science/ article/pii/S1525730415000832.

16. Dolled-Filhart M, Roach C, Toiand G, Stanforth D, Jansson M, Lubiniecki GM, Ponto G, Emancipator K. Development of a companion diagnostic for Pembrolizumab in non-small cell lung cancer using immunohistochemistry for programmed death ligand-1. Arch Pathol Lab Med. 2016;140:1243-9 https://www.archivesofpathology.org/doi/10.5858/ arpa.2015-0542-OA?url_ver=Z39.88-2003\&rfr_id=ori:rid:crossref.org\&rfr_ dat=cr_pub\%3dpubmed.

17. Urska J, Izidor K, Andrej J, Luka C, Tanja C. PD-L1 expression in squamous-cell carcinoma and adenocarcinoma of the lung. Radiol Oncol. 2017:51:357-62 https://www.ncbi.nlm.nih.gov/pmc/articles/PMC5612001/. 
18. Scheel AH, Ansén S, Schultheis AM, Scheffler M, Fischer RN, Michels S, Hellmich M, George J, Zander T, Brockmann M, et al. PD-L1 expression in non-small cell lung cancer: correlations with genecic alterations. Oncoimmunology. 2016;5:e1131379 https://www.ncbi.nlm.nih.gov/pmc/ articles/PMC4910698/.

19. Lin G, Fan X, Zhu W, Huang C, Zhuang W, Xu H, Lin X, Hu D, Huang Y, Jiang $\mathrm{K}$, et al. Prognostic significance of PD-L1 expression and tumor infiltrating lymphocyte in surgically resectable non-small lung cancer. Oncotarget. 2017;8:83986-94 https:/www.ncbinlm.nih.gov/pmc/articles/PMC5663570/

20. Miyazawa T, Marushima H, Saji H, Kojima K, Hoshikawa M, Takagi M, Nakamura H. PD-L1 expression in non-small-cell lung cancer including various adenocarcinoma subtypes. Ann Thorac Cardiovasc Surg. 2018. https://doi.org/10.5761/atcs.oa.18-00163 https://www.jstage.jst.go.jp/ article/atcs/25/1/25_oa.18-00163/_article.

21. Vilain RE, Menzies AM, Wilmott JS, Kakavand H, Madore J, Guminski A, Liniker E, Kong BY, Cooper AJ, Howle JR, et al. Dynamic changes in PD-L1 expression and immune infiltrates early during treatment predict response to PD-1 blockade in melanoma. Clin Cancer Res. 2017;23(17):5024-33. https://doi.org/10.1158/1078-0432.CCR-16-0698 Epub 2017 May 16. http://clincancerres.aacrjournals.org/content/23/17/5024.long.

\section{Publisher's Note}

Springer Nature remains neutral with regard to jurisdictional claims in published maps and institutional affiliations.

Ready to submit your research? Choose BMC and benefit from:

- fast, convenient online submission

- thorough peer review by experienced researchers in your field

- rapid publication on acceptance

- support for research data, including large and complex data types

- gold Open Access which fosters wider collaboration and increased citations

- maximum visibility for your research: over $100 \mathrm{M}$ website views per year

At $\mathrm{BMC}$, research is always in progress.

Learn more biomedcentral.com/submissions 